\title{
COVID-19: An Overview about the Disease Etiology and its Prevention
}

\section{Nayab Mustansar* and Rizwan Rafi}

Assistant Professor, Consultant Nuclear Physician, Islamabad, Pakistan

*Corresponding Author: Nayab Mustansar, Assistant Professor, Consultant Nuclear Physician, Islamabad, Pakistan.
Received: March 24, 2020

Published: April 03, 2020

(C) All rights are reserved by Nayab

Mustansar and Rizwan Rafi.

\begin{abstract}
Coronaviruses are zoonotic, meaning they are transmitted between animals and people. Common signs of infection include respiratory symptoms, fever, cough, shortness of breath and breathing difficulties [2]. In more severe cases, infection can cause pneumonia, severe acute respiratory syndrome, kidney failure and even death [3].

Detailed investigations found that SARS-CoV was transmitted from civet cats to humans and MERS-CoV from dromedary camels to humans. Several known coronaviruses are circulating in animals that have not yet infected humans [1-3].

This article is based on the overview regarding the disease etiology and its prevention to educate the mass population.

Keywords: Corona Virus; Military Camps; Zoonotic Components; WHO Guidance; ConV
\end{abstract}

\section{Aetiology}

At the end of 2019, a new variant of Sarbeco Virus subgenus of Corona Viridae family was found in the Broncho-alveolar Lavage samples taken from different group of patients coming to the hospital with signs and symptoms of pneumonia, in Wuhan City of Hubei Province of China. The new variant was therefore termed as Severe Acute Respiratory Syndrome Corona Virus 2 (SARS CoV-2), formerly known as Beta Corona Virus [4]. It is important to mention that the newly identified Corona Virus has similarities with severe acute respiratory syndrome (SARS) Corona Viruses found in bats [5].

The newly identified Corona Viruses are basically enveloped RNA viruses. They are sub divided into strains that spread diseases in human beings like common cold, SARS, MERS etc. and strains that effect mammals (like bats and camels) and birds [6]. Unlike SARS and MERS, it is not very frequent that a strain of Animal Corona Virus may affect Human beings and spread further.

History taken from most of the patients carrying the disease suggested that the spread of Corona Virus was somehow connected with Huanan South China Sea-food Market, which is a live animal market. This proves that the virus originates in animals and then transmitted to Humans. Until now, both the intermediate host and animal reservoir have not been identified. Yet, there are many case studies giving an idea that there can be a recombination between the bat coronavirus and an origin-unknown coronavirus which might have given rise to this new strain but this theory needs con- firmation [7]. The symptoms are shown in figure 1, moreover the most common to rare symptoms are shown in figure 2 .

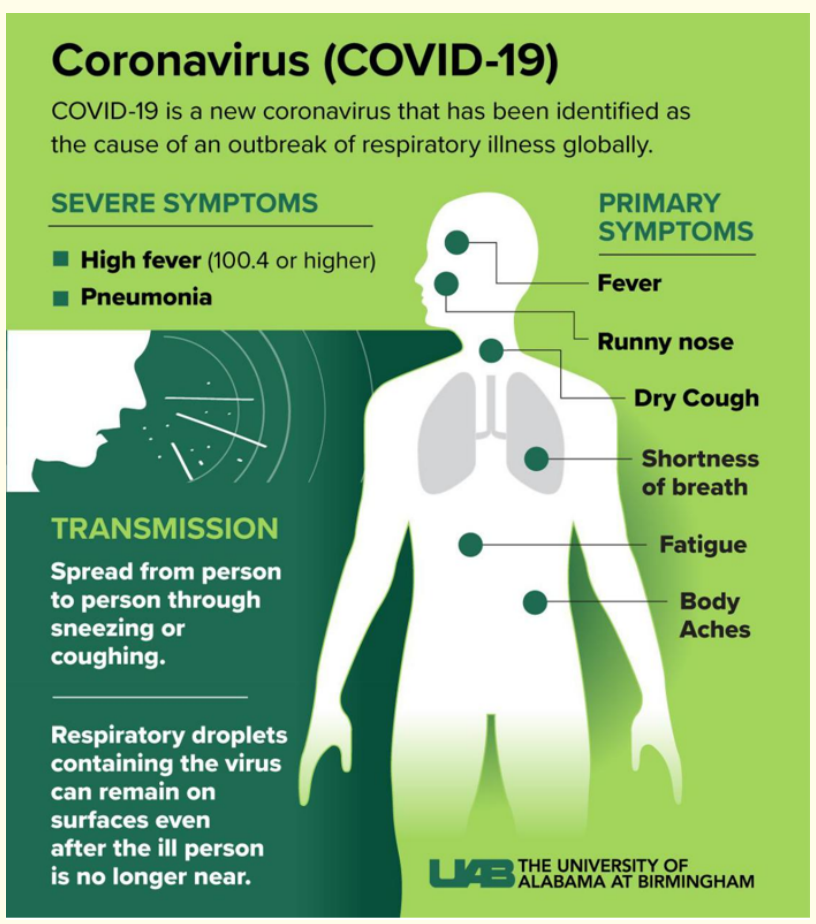

Figure 1

At present, there is no exact confirmation regarding how the virus gets transmitted, which is making the situation worse. It has been observed that inside and outside China, the virus main- 


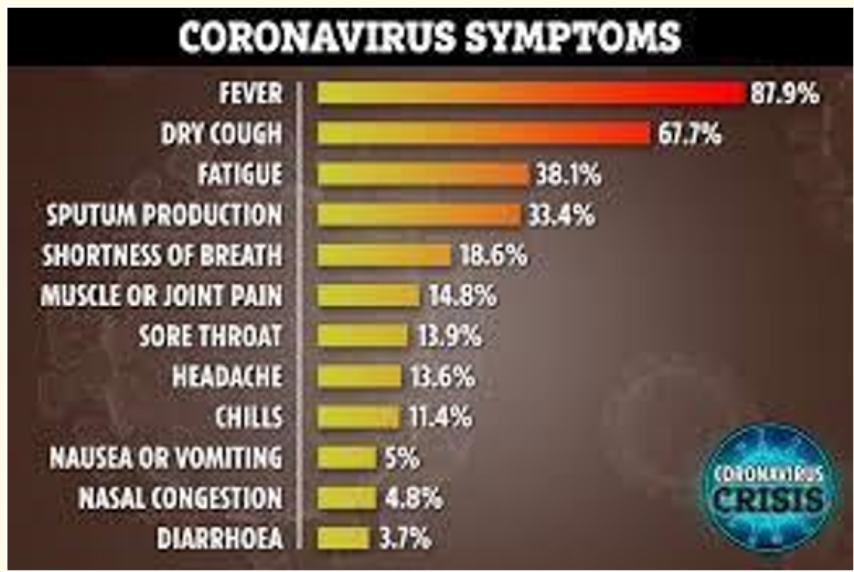

Figure 2

ly spread by person-to-person contact. As a result of preliminary evaluation regarding the transmission and spread of Corona virus, it was observed that out of the first 425 confirmed cases of Covid, before 1st January 2020, 55\% cases were interrelated to the Huanan South China Seafood Market, however 8.6\% of cases had a connection with above mentioned market after 1st January 2020. It was a confirmation that after mid of December 2019, the Virus spread because of person to person contact specially in the healthcare staff. During a study conducted on five patients of Covid in Shenzen City, who had a travel history to Wuhan city and all were family members too, it was observed that the disease spread among them mainly because of person to person contact. Another study in one case series concluded that the ratio of Nosocomial transmission between patients and healthcare workers was $41 \%$. It seems a greater degree of ambiguity in the spread of this virus among the humans. Co-Vid has a resemblance with SARS and MERS that upon coughing and sneezing, respiratory droplets are produces, which are the main reason of spread of Co-Vid amongst humans. As the Virus has been detected in Blood, there are chances of fecal transmission. It is very important to mention here that Corona Virus has also been detected in saliva. It has also been noticed in the endemic areas that the disease spread via an asymptomatic contact. Circumstantial reports suggest that some people can act as super transmitters early in the course of their infection and these individuals can pass on the infection, to outsized numbers of contacts, involving healthcare workers [8]. The same statistics were also observed in the spread of similar diseases like Ebola, MERS and SARS. Adding to the subject, there is till no information whether there are chances of transmission of the disease through breastfeeding or perinatal transmission. Retrospective assessments of Co-Vid infected pregnant women revealed that there are no proofs for intrauterine infection caused by vertical transmission. However, the risk of transmission to the newborn during vaginal delivery still needs to be evaluated [9].

\section{Primary prevention}

- Avoiding any kind of exposure to the virus is the simplest way to stop the spread of infection. Some recommendations in this regard are as under [10]:
- Always wash your hands with soap and water for more than 20 seconds. Any alcohol-based hand sanitizer can also be used to clean the hands. It is very risky to touch the mouth, eyes and nose with unwashed hands.

- Try to keep a distance of at least 03 feet from all individuals specially those who are having the symptoms of cough, fever or sneezing.

- Keep you mouth and nose covered while coughing or sneezing and discard the disposable masks, tissues immediately after use in a closed bin and wash you hands afterwards.

- If there are any symptoms of cough, fever, headache and difficulty in breathing, immediately talk to your doctor and share all the details with him including the travel history and contact history.

- While visiting live animals' market in affected areas, wear a mask and use gloves. Avoid touching the surfaces with bare hands and wash your hands immediately in case of any contact.

\section{Medical masks}

- As per the advice of World Health Organization (WHO), there is no need to wear a mask in the community settings if there are no symptoms of cough, fever and sneezing. Nevertheless, the local cultural habits in some countries require the use of medical mask. Persons having fever or any kind of respiratory symptoms are recommended to wear a mask, specifically in endemic zones.

Screening and quarantine

- One of the most important tasks is to screen the individuals coming from the endemic areas by checking their temperature and signs and symptoms of infection. Additionally, asking questions from them about their travel history and any kind of contact with the infected individuals.

- There is another concept of Collective screening of passengers travelling through airlines upon leaving the endemic zones and arriving in any other city/country. Though this exercise has still not been fruitful and there are chances of missing more than $50 \%$ of the cases of COVID-19, specifically the ones who were showing no symptoms because of going through an incubation period.

- In some Countries, quarantine of easily identifiable individuals with signs and symptoms of COVID-19 was done forcefully to prevent the further spread of the disease but the forceful quarantine may have ever-lasting repercussions with psychosocial effects.

Vaccine

- Presently, vaccines are not available in the market but preparation of vaccines against COVID-19 is under process and it may take 10 months or more for the first sample to get availability in the open market. 


\section{Screening for travellers}

- $\quad$ People going to or coming from the affected areas must be screened upon their arrival or departure [11].

- A 14 days self assessment is advised to the individuals coming back from the endemic zones while entering into any other country. In some countries, enforced quarantine is the law for the travellers returning from affected areas.

- If in case, a traveller observes any symptom of COVID-19, telephone contact must immediately be made with the local health care provider $[9,10]$.

\section{Secondary prevention}

- In order to inhibit the spread of the disease, it is very important to recognize the symptoms beforehand.

- Any confirm or suspected cases should be quarantined immediately and the standard operating procedures for the control and prevention of the disease should be adopted [12].

- $\quad$ All the suspected cases should be reported to the local authorities at once.

\section{Bibliography}

1. WHO: novel coronavirus (COVID-19) situation dashboard.

2. WHO: coronavirus disease (COVID-2019) situation reports.

3. CDC: coronavirus disease 2019 (COVID-19) in the US.

4. CDC: locations with confirmed COVID-19 cases.

5. National Health Committee of the People's Republic of China: outbreak report.

6. GenBank.

7. WHO: coronavirus disease (COVID-19) advice for the public.

8. BMJ: facemasks for the prevention of infection in healthcare and community settings.

9. WHO: infection prevention and control during health care when novel coronavirus ( $\mathrm{nCoV}$ ) infection is suspected.

10. CDC: interim infection prevention and control recommendations for patients with confirmed coronavirus disease 2019 (COVID-19) or persons under investigation for COVID-19 in healthcare settings.

11. CDC: flowchart to identify and assess coronavirus disease 2019 (COVID-19).

12. WHO: global surveillance for human infection with coronavirus disease (COVID-19).

\section{Assets from publication with us}

- Prompt Acknowledgement after receiving the article

- Thorough Double blinded peer review

- Rapid Publication

- Issue of Publication Certificate

- High visibility of your Published work

Website: www.actascientific.com/

Submit Article: www.actascientific.com/submission.php Email us: editor@actascientific.com

Contact us: +919182824667 